\title{
Emodin attenuates TNF- $\alpha$-induced apoptosis and autophagy in mouse C2C12 myoblasts though the phosphorylation of Akt
}

Dexiu Chen ${ }^{a, b, 1}$, Junshan Liu ${ }^{b}$ Lu Lu $^{\text {a, b }}$, Yanfeng Huang ${ }^{a, b}$, Yanjing Wang ${ }^{a, b}$, Mingqing Wang ${ }^{\text {a, }}$, Yangyang Liu ${ }^{\text {a, b }}$, Dandan Xie ${ }^{\text {a, b }}$, Jiebing Chen ${ }^{\text {a, b }}$, Jianxin Diao ${ }^{\text {b }}$, Lianbo Wei ${ }^{\text {a, b, * }}$, Ming Wang ${ }^{\text {a, b, * }}$

${ }^{a}$ Department of Traditional Chinese Medicine, ZhuJiang Hospital, Southern Medical University, Guangzhou, Guangdong, 510280, P. R. China

${ }^{\mathrm{b}}$ School of Traditional Chinese Medicine, Southern Medical University, Guangzhou, Guangdong, 510515, P. R. China

*Corresponding author, Lianbo Wei, Ph. D, Professor

Department of Traditional Chinese Medicine, ZhuJiang Hospital, Southern Medical University, Guangzhou, Guangdong, 510280, P. R. China

E-mail: 54140527@qq.com

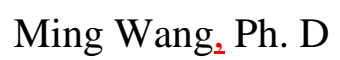

Department of Traditional Chinese Medicine, ZhuJiang Hospital, Southern Medical University, Guangzhou, Guangdong, 510280, P. R. China

E-mail: Youxin624113@163.com 
Abstract: Emodin, a major component of Rheum palmatum, has been reported to significantly protect neural tissue against apoptosis and autophagy. However, the effects and underlying mechanisms of action of emodin in muscle atrophy are still poorly defined. In this study, we investigated the protective effects and the underlying mechanisms by which emodin acts on tumor necrosis factor alpha (TNF- $\alpha$ )-induced apoptosis and autophagy in mouse $\mathrm{C} 2 \mathrm{C} 12$ myoblasts. Emodin, at various concentrations $_{2}$ decreased TNF- $\alpha$-induced apoptosis in $\mathrm{C} 2 \mathrm{C} 12$ myoblasts, which were analyzed by Hoechst 33342 staining and annexin V/PI analysis. Emodin also inhibited the collapse of the mitochondrial membrane potential and the generation of reactive oxygen species in TNF- $\alpha$-stimulated $\mathrm{C} 2 \mathrm{C} 12$ myoblasts. Consistent with these results, the expression of Bcl-2 was increased, whereas the expression of Bax, cleavedcaspase 3 and cleaved-PARP was decreased after emodin treatment. These data demonstrate that emodin attenuated apoptosis in TNF- $\alpha$-stimulated $\mathrm{C} 2 \mathrm{C} 12$ myoblasts through mitochondrial signaling pathways. In addition, emodin inhibited autophagy in TNF- $\alpha$-stimulated C2C12 myoblasts by suppressing the expression of LC3-II, Beclin1 and Atg7. Emodin also resulted in the upregulation of the phosphorylated forms of Akt. Taken together, these results suggest that emodin inhibited apoptosis and autophagy in TNF- $\alpha$-induced $\mathrm{C} 2 \mathrm{C} 12$ myoblasts, possibly through the activation of phosphorylated Akt. Our findings suggest that emodin could be a potential therapeutic agent in the treatment of muscle atrophy.

Keywords: C2C12 myoblasts; Apoptosis; Autophagy; Tumor necrosis factor alpha; Emodin 


\section{Introduction}

Skeletal muscle atrophy is defined as the deficiency of both muscle mass and muscle function, which is caused by an imbalance between protein degradation and synthesis. Muscle atrophy appears in response to various types of physiological and pathological stimuli, including aging, chronic kidney disease (CKD), cancer, diabetes, muscle disuse and malnutrition $[1,2]$. Pro-inflammatory cytokines, such as tumor necrosis factor alpha (TNF- $\alpha$ ), are involved in this process. The level of TNF- $\alpha$ plays a critical role in muscle atrophy through its effects on cell growth and myogenic differentiation inhibition, and apoptosis and through the induction of autophagy [3-7].

Muscle fibers are post-mitotic syncytia formed by the fusion of myogenic progenitors during pre- and post-natal development [8]. The bulk of aggregated myonuclei develop into fibers during post-natal growth, leading to a dramatic increase in muscle mass [9]. Recent research has demonstrated that apoptosis eliminates superfluous tissues during normal embryonic development [10]. In addition, apoptosis is important for the preservation of tissue homeostasis in adults [10]. The progressive elimination of myonuclei via apoptosis may drive the onset and progression of muscle atrophy [11-14]. In vertebrates, apoptosis is induced by two major pathways, mitochondrion-mediated signaling and death receptor-mediated apoptotic signaling. In apoptotic cells, caspase-9 is activated [15], and this leads to the activation and cleavage of executioner caspases-3 and -7 [16, 17]. The critical downstream protein PARP is cleaved in this process [18]. These are the typical characteristics of mitochondrion-mediated apoptosis. Additionally, studies on death receptor pathways have indicated that death receptors, such as Fas, TNFR1, and TRAIL, contribute to the activation of caspase- 8 and caspase- 3 as well as the cleaving of PARP $[19,20]$. As 
a result, caspase-3 and PARP are potential links between the mitochondrion-mediated pathway and the death receptor-mediated apoptotic pathway.

Research show $\underline{s}$ that the autophagic system also contributes to muscle atrophy. Clinical studies have reported that autophagy is a significant characteristic of myopathic conditions $[21,22]$. Some studies have shown that the autophagy-related genes LC3, Beclin1 and Atg12 are upregulated in different models of muscle atrophy $[23,24]$. Indeed, we have reported in previous research that TNF- $\alpha$ was expressed by $\underline{\mathrm{C}} 2 \mathrm{C} 12$ myoblasts during muscle atrophy and that $\mathrm{TNF}-\underline{\alpha}$ alone or in combination with other cytokines stimulated the apoptosis and autophagy of $\mathrm{C} 2 \mathrm{C} 12$ myoblasts [2527]·

Emodin (1,3,8-trihydroxy-6-methylanthraquinone), a key anthraquinone derivative of Rheum palmatum, exhibits anti-inflammatory, anti-fibrotic, anti-tumor, and antiatherosclerotic effects $[18,28-33]$. However, the role of emodin in TNF- $\alpha$-induced apoptosis and autophagy in $\mathrm{C} 2 \mathrm{C} 12$ myoblasts_is unknown. This study presents the first demonstration that emodin can inhibiteinhibit apoptosis and autophagy in TNF$\alpha$-stimulated $\mathrm{C} 2 \mathrm{C} 12$ myoblasts. Our findings shed light on the potential of emodin to modulate apoptosis and autophagy as a novel therapeutic strategy for the treatment of muscle atrophy, and they further promote our understanding of this field.

\section{Materials and methods}

\subsection{Chemicals and reagents}

5,5',6,6'-tetrachloro-1,1',3,3'-tetraethylbenzimidazolylcarbocyanine iodide (JC-1) probes were purchased from Cayman (Ann Arbor, MI, USA). The annexin V-FITC apoptosis detection kit and RIPA lysis buffer were purchased from Keygen (Nanjing, China). The BCA protein assay kit was purchased from Thermo Fisher (Pittsburgh, PA). Antibodies were purchased from Cell Signaling Technologies (Danvers, MA). 
Recombinant rat TNF- $\alpha$ was purchased from PeproTech (Rocky Hill, NJ). All other chemicals were purchased from Sigma (Saint-Louis, MO).

\subsection{Cell culture}

C2C12 myoblasts were purchased from type culture collection of the Chinese

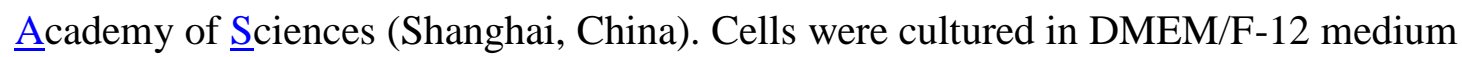
(HyClone) supplemented with 10\% (v/v) fetal bovine serum (FBS, HyClone), 100 $\mathrm{U} / \mathrm{ml}$ penicillin, and $100 \mu \mathrm{g} / \mathrm{ml}$ streptomycin (Invitrogen) in a humidified incubator containing $5 \% \mathrm{CO}_{2}$ at $37^{\circ} \mathrm{C}$.

\subsection{Cytotoxicity assay}

C2C12 myoblasts were seeded at a density of $1 \times 10^{4} / \mathrm{ml}$ in 96 -well plates and

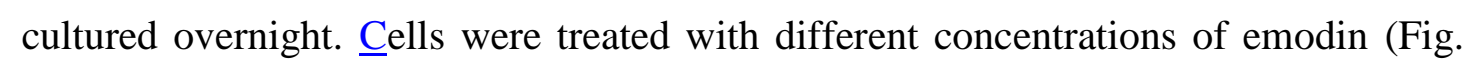
$1 \mathrm{~A}$, purity (HPLC) $\geqslant 98 \%$, Sigma) for $24 \mathrm{~h}$. Then, $20 \mu \mathrm{l}$ of MTT ( $5 \mathrm{mg} / \mathrm{ml}$, Sigma) was added and incubated for another $4 \mathrm{~h}$. After this, the supernatants in each well were removed and $150 \mu$ of DMSO was added into each well followed by incubation at $37{ }^{\circ} \mathrm{C}$ for $10 \mathrm{~min}$ with gentle shaking. The optical density was detected at $490 \mathrm{~nm}$

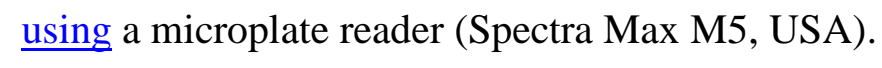

\subsection{Hoechst 33342 staining}

Hoechst 33342 dye was used to evaluate the occurrence of apoptosis based on the aggregation of chromatin and the fragmentation of the nuclei in the cells. $\mathrm{C} 2 \mathrm{C} 12$ myoblasts were plated in 6-well plates and treated with emodin in the presence or absence of TNF- $\alpha(20 \mathrm{ng} / \mathrm{ml})$ for $24 \mathrm{~h}$. Then, cells were incubated with $10 \mu \mathrm{g} / \mathrm{ml}$ Hoechst 33342 dye for $20 \mathrm{~min}$ at $37{ }^{\circ} \mathrm{C}$ and rinsed with cold phosphate buffered saline (PBS). The cells were immediately observed with a fluorescence microscope (Eclipse-Ti, Nikon, Japan) using filters for blue fluorescence. To quantify the extent of apoptosis, the frequency of apoptotic cells (\%) was calculated from five images of randomly selected microscopic fields of view from each treatment. The percent of 
apoptotic cells was calculated as the total number of nuclei that were apoptotic relative to the overall number of cells observed. Apoptotic nuclei were identifiable because they appeared bright and condensed compared to normal nuclei.

\subsection{Apoptosis assay}

Apoptosis was assessed using the annexin V-FITC apoptosis detection kit according to the manufacturer's instruction. $\mathrm{C} 2 \mathrm{C} 12$ myoblasts were seeded in 6-well plates and incubated with emodin in the presence or absence of TNF- $\alpha(20 \mathrm{ng} / \mathrm{ml})$ for 24 h. Cells were harvested, washed twice with cold PBS, and resuspended in binding buffer at $1 \times 10^{5}$ cells $/ \mathrm{ml}$. A $250 \mu$ laliquot of the suspension was incubated with $5 \mu \mathrm{l}$ of annexin_V-EGFP and $5 \mu \mathrm{l}$ of propidium iodide (PI, $20 \mu \mathrm{g} / \mathrm{ml}$ ) in the dark at room temperature for $15 \mathrm{~min}$, and the samples were analyzed with a flow cytometer (BD Biosciences, USA). Cells that were positive for annexin_V but negative for PI were considered to be undergoing apoptosis. The third quadrant cells were regarded as control cells, whereas the first and the fourth quadrant cells were considered as apoptosis, the percent of apoptotic cells was calculated as the first and the fourth quadrant cells relative to the overall number of cells.

\subsection{Mitochondrial membrane potential $(\Delta \Psi \mathrm{m})$ measurement}

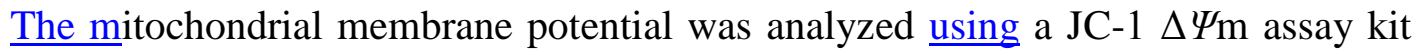
according to the manufacturer's protocol. In brief, $\mathrm{C} 2 \mathrm{C} 12$ myoblasts were seeded in 6well plates and incubated with emodin in the presence or absence of TNF- $\alpha(20 \mathrm{ng} / \mathrm{ml})$ for $24 \mathrm{~h}$. Then, the cells were collected and resuspended in a JC-1 working solution and incubated at $37{ }^{\circ} \mathrm{C}$ in $5 \% \mathrm{CO}_{2}$ for $15 \mathrm{~min}$. Next, the cells were collected and washed in incubation buffer twice. Then, the stained cells were assayed using a flow cytometer (BD Biosciences, USA).

\subsection{Autophagosome and ROS observations}


After emodin treatment with or without TNF- $\alpha(20 \mathrm{ng} / \mathrm{ml})$, the cells were fixed with $4 \%$ paraformaldehyde for $30 \mathrm{~min}$ at room temperature, permeabilized with $0.2 \%$ Triton X-100 for 5 min and blocked with $1 \%$ FBS containing $0.25 \%$ Tween-20 for 30 min at room temperature. Then, cells were incubated overnight with anti-LC3B antibody (1:200 dilution). After washing with PBS, the cells were incubated with the appropriate secondary antibody for $1 \mathrm{~h}$ at room temperature. Cells were then rinsed and counterstained with DAPI for 15 min. Images were obtained using confocal microscopy (Carl Zeiss LSM710, Jena, Germany).

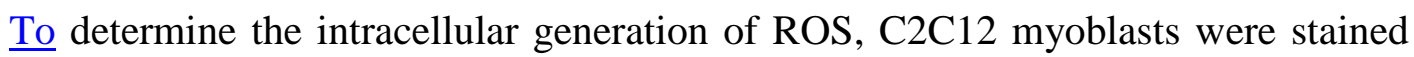
with a 2'-7'-dichlorofluorescein diacetate $\left(\mathrm{H}_{2} \mathrm{DCF}-\mathrm{DA}\right)$ fluorescent probe ( $\underline{\text { Sigma}}$ ). Cells were incubated with $\mathrm{H}_{2}$ DCF-DA $(10 \mu \mathrm{M})$ for 20 min at $37{ }^{\circ} \mathrm{C}$ and washed with PBS and then counterstained with DAPI for 15 min. Images were obtained using confocal microscopy (Carl Zeiss LSM710, Jena, Germany).

\subsection{Western blotting analysis}

C2C12 myoblasts were collected and washed twice with ice-cold PBS and then lysed for 30 min at $4{ }^{\circ} \mathrm{C}$ with RIPA buffer containing a cocktail of protease inhibitors. Samples of the cell lysates were separated by $10 \%$ SDS-PAGE_ and subsequently transferred onto a polyvinylidene difluoride (PVDF) membrane. The membranes were blocked with 5\% skim milk in Tris-buffered saline containing 0.1\% Tween 20 (TBST) on the shaker at room temperature for $1 \mathrm{~h}$ and then incubated with primary antibodies at $4{ }^{\circ} \mathrm{C}$ overnight. Subsequently, the membranes were washed with TBS-T followed by_an incubation with the HRP-conjugated secondary antibodies at room temperature for $1 \mathrm{~h}$. Images were obtained and analyzed with a CCD system (Image Station 2000 MM, Kodak).

\subsection{Statistical analysis}


Statistical analyses were performed with SPSS_13.0 (SPSS, Chicago, IL). All data were presented as the means \pm SD from at least 3 independent experiments. Statistical significance was determined using one-way analysis of variance (ANOVA) followed by the Tukey-Kramer test for multiple comparisons. A value of $P_{-}<-0.05$ was considered statistically significant.

\section{Results}

\subsection{Emodin shows no obvious cytotoxicity in $\mathrm{C} 2 \mathrm{C} 12$ myoblasts below $20 \mu \mathrm{M}$}

In the present study, we first investigated whether emodin exhibited any potential cytotoxic effects on $\mathrm{C} 2 \mathrm{C} 12$ myoblasts using an MTT assay. After incubation with emodin for $24 \mathrm{~h}$, low concentrations $(1 \sim 20 \mu \mathrm{M})$ of emodin had no obvious influence on cell viability. However, a high concentration $(30 \mu \mathrm{M})$ of emodin significantly decreased the viability of $\mathrm{C} 2 \mathrm{C} 12$ myoblasts (Fig. 1B). Based on the results above, 5, 10 and $20 \mu \mathrm{M}$ emodin were used in our next experiments.<smiles>Cc1cc(O)c2c(c1)C(=O)c1cc(O)cc(O)c1C2=O</smiles>

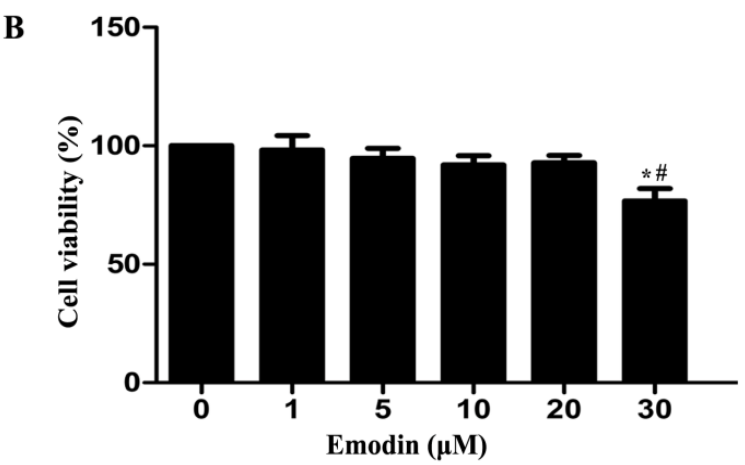

Fig. 1. Chemical structure of emodin and its effect on the viability of $\mathrm{C} 2 \mathrm{C} 12$ myoblasts. (A) Chemical structure of emodin. (B) The effects of emodin on the viability C2C12_myoblasts. C2C12 myoblasts were cultured with different

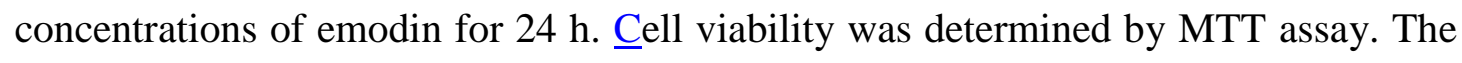
values are presented as the means \pm SD of three independent experiments. ${ }^{*} P<0.05$ compared with the TNF- $\alpha$ group ${ }^{\#} P<0.05$ compared with the control cells. 


\subsection{Emodin suppresses TNF- $\alpha$-induced apoptosis in $\mathrm{C} 2 \mathrm{C} 12$ myoblasts through the mitochondrial apoptosis pathway.}

Our previous studies have shown that pathologic levels of TNF- $\alpha$ can induce apoptosis in $\mathrm{C} 2 \mathrm{C} 12$ myoblasts [25]. Therefore, we further investigated whether emodin could protect these cells against TNF- $\alpha$-induced apoptosis.

As shown in Fig. 2A, C2C12 myoblasts were incubated with emodin in the presence or absence of TNF- $\alpha(20 \mathrm{ng} / \mathrm{ml})$ for $24 \mathrm{~h}$ and then stained with Hoechst 33342 dye. The TNF- $\alpha$-treated cells exhibited apoptotic morphological characteristics with nuclear condensation and DNA fragmentation. In contrast, TNF- $\alpha$-induced apoptosis was efficiently abrogated by treatment with emodin. $\underline{\text { In particular, treatment }}$ with $10 \mu \mathrm{M}$ emodin showed better anti-apoptotic effects than did the other treatments.

We subsequently examined the apoptotic ratio using flow cytometry with annexin V/PI staining (Fig. 2B). We found that the percentage of cells undergoing apoptosis (but not necrosis) increased after treatment with TNF- $\alpha$ but that emodin treatment significantly down-regulated TNF- $\alpha$-induced apoptosis in $\mathrm{C} 2 \mathrm{C} 12$ myoblasts. These results were consisted with that of Hoechst staining.

Mitochondrial potential $(\Delta \Psi \mathrm{m})$ has been reported to be associated with apoptosis through the exposure of cytochrome $c$ to the inter-membrane space $[34,35]$. To confirm whether emodin affects the cellular $\Delta \Psi \mathrm{m}$, fluorescent JC-1 probes were used. Our data suggest that the $\Delta \Psi \mathrm{m}_{2}$ in response to treatment with TNF- $\alpha_{2}$ was significantly decreased compared to that of the control cells. Emodin treatment blocked the TNF- $\alpha$-induced decrease in $\Delta \Psi \mathrm{m}$, especially at $10 \mu \mathrm{M}(\underline{\text { Fig. } 2} \mathrm{C})$.

Emodin has been shown to be a potent ROS scavenger [36]. Therefore, we speculated that ability of emodin to reduce TNF- $\alpha$-induced apoptosis might be attributable to the same property. To confirm this hypothesis, we measured ROS 
production using CM-H2DCF-DA staining. Our results show that TNF- $\alpha$ treatment led to strong H2DCF-DA staining, whereas emodin treatment decreased the staining intensity. These results indicate that emodin has a protective effect against TNF- $\alpha$ induced ROS production (Fig. 2 D).

Western blotting analysis results show that the Bcl-2/Bax ratio was reduced and that the cleaved-caspase 3 and cleaved-PARP expression levels were increased in the TNF- $\alpha$ group. However, emodin treatment led to an increase in the Bcl-2/Bax ratio and the decrease of both cleaved-caspase 3 and cleaved-PARP (Fig. 2 E \& F). Collectively, these results suggest that emodin inhibits $\mathrm{C} 2 \mathrm{C} 12$ myoblast apoptosis induced by TNF- $\alpha$ through the mitochondrial pathway. 

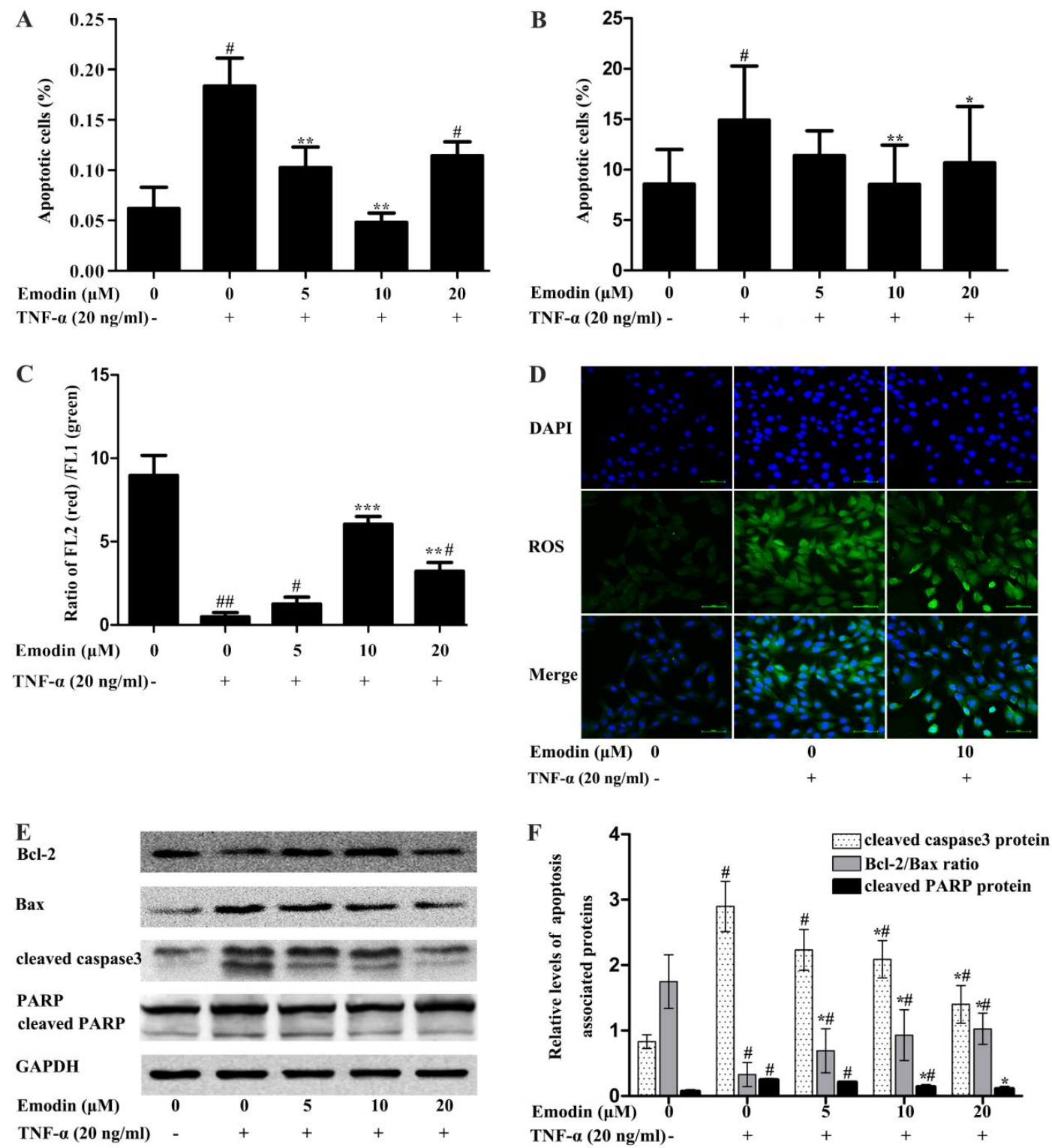

Fig. 2. Emodin ameliorates TNF- $\alpha$-induced-apoptosis in $\mathrm{C} 2 \mathrm{C} 12$ myoblasts through the mitochondrial pathway. $\mathrm{C} 2 \mathrm{C} 12$ myoblasts were plated in 6-well plates and treated with emodin in the presence or absence of TNF- $\alpha(20 \mathrm{ng} / \mathrm{ml})$ for $24 \mathrm{~h}$. Cells incubated with $10 \mu \mathrm{g} / \mathrm{ml}$ Hoechst 33342 dye were observed under a fluorescence microscope (A) or analyzed to determine the apoptotic rate (B) and mitochondrial membrane potential (C) by flow cytometry. (D) Emodin decreases the generation of ROS in C2C12 myoblasts induced by TNF- $\alpha$. C2C12 myoblasts were plated in 6-well plates and treated with emodin in the presence or absence of TNF- $\alpha(20 \mathrm{ng} / \mathrm{ml})$ for $24 \mathrm{~h} . \mathrm{C} 2 \mathrm{C} 12$ 
myoblasts were loaded with $\mathrm{H}_{2}$ DCF-DA and DAPI and observed under a fluorescence microscope $(400 \times)$. (E) Emodin regulates the expression levels of apoptosis-related proteins. C2C12 myoblasts were incubated with emodin in the presence or absence of TNF- $\alpha(20 \mathrm{ng} / \mathrm{ml})$ for $24 \mathrm{~h}$. After treatment, the expression of PARP, cleaved-caspase 3, Bcl-2 and Bax was determined by western blotting. GAPDH were used as a loading control. (F) The quantification of the expression levels of apoptosis-related proteins. Data derived from three separate experiments are presented as the means \pm SD. ${ }^{*} P<$ 0.05 compared with the TNF- $\alpha$ group, ${ }^{\#} P<0.05$ compared with control cells.

\subsection{Emodin inhibits TNF-a-induced autophagy in C2C12 myoblasts}

TNF- $\alpha$-induced upregulation of autophagy had been demonstrated previously [27, 37,38 . We further investigated the effects of emodin on TNF- $\alpha$-induced autophagy in $\mathrm{C} 2 \mathrm{C} 12$ myoblasts. LC3 is a marker for the autophagic process and an upregulation of LC3 is required to replenish the LC3 protein pool and allow for the progression of autophagy [2]. To determine the cellular expression levels of the autophagosome marker LC3B, we used immunofluorescent staining in C2C12 myoblasts in response to emodin treatment. The previous experimental results showed that treatment with 10 $\mu \mathrm{M}$ emodin exhibited the best protective effects against TNF- $\alpha$. Therefore, in this experiment, emodin at a concentration of $10 \mu \mathrm{M}$ was used with the treatment group. The results from fluorescence microscopy revealed that the expression of LC3B (red) was abundant in the TNF- $\alpha$ group (Fig. 3A), but those effects were reduced after emodin treatment.

Next, we determined whether emodin could protect against the autophagy induced by TNF- $\alpha$ in C2C12 myoblasts. It was observed that TNF- $\alpha$ induced an increase in the expression of LC3-II (autophagosomal membrane-localized form). However, emodin treatment limited the increase in LC3-II that was induced by TNF- $\alpha$ (Fig. 3 B \& C). 
Beclin-1 and Atg7 are considered to be important genes in the canonical autophagy pathway and are required for autophagosome formation [39]. In our findings, the expression patterns of Beclin-1 and Atg7 were consistent with those of LC3-II in the emodin-treated group (Fig. 3 B \& C). Consequently, these results indicate that emodin can repress TNF- $\alpha$-induced autophagy in $\mathrm{C} 2 \mathrm{C} 12$ myoblasts.

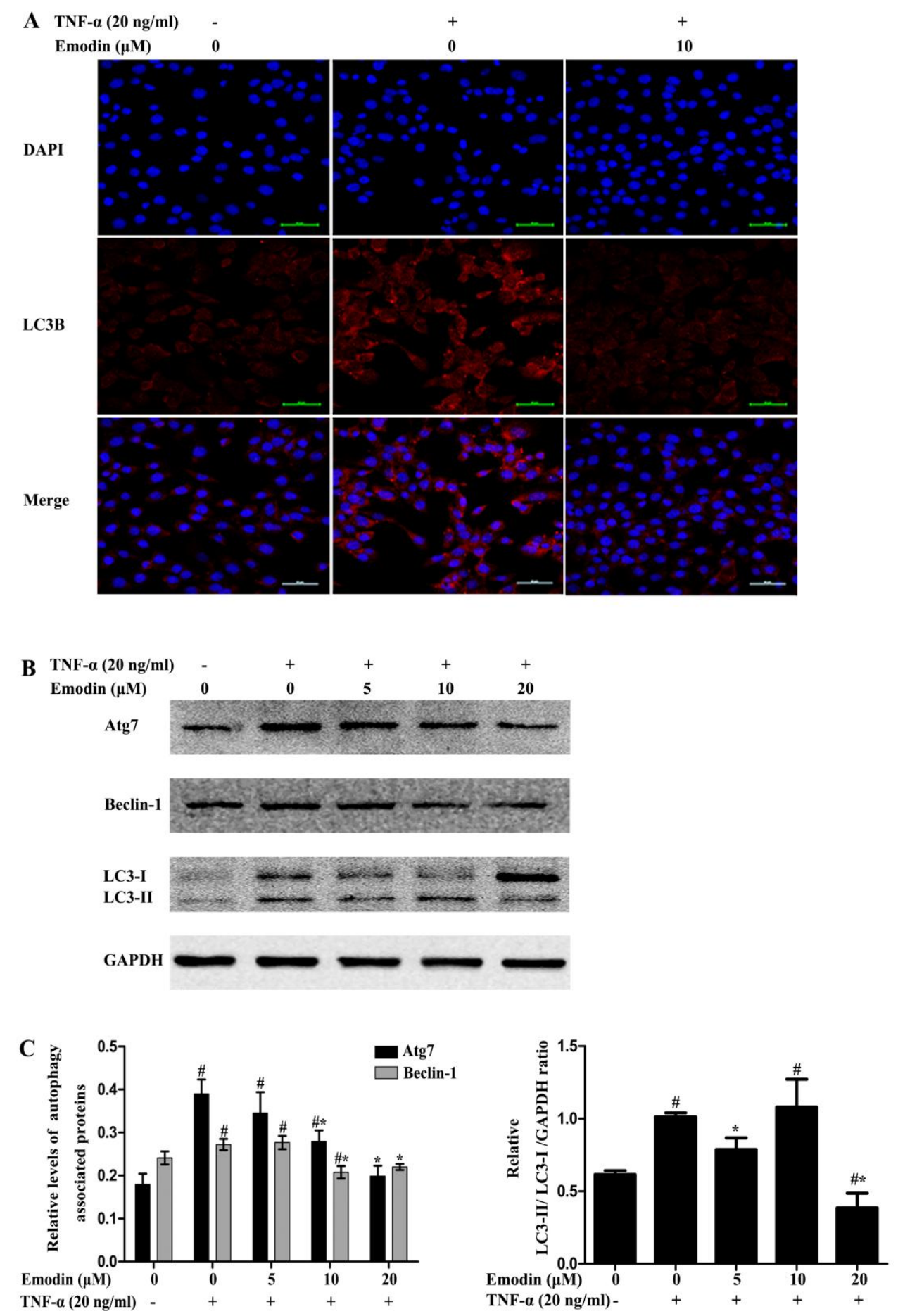


Fig. 3. Emodin inhibits TNF- $\alpha$-induced autophagy in $\mathrm{C} 2 \mathrm{C} 12$ myoblasts. (A) Immunofluorescence analysis of the autophagosome marker LC3B in C2C12 myoblasts. The cells were stained with an antibody against LC3B (red) and with the nuclear dye DAPI (blue) (400x). (B) Emodin regulates the expression levels of autophagy-related proteins. $\mathrm{C} 2 \mathrm{C} 12$ myoblasts were incubated with emodin in the presence or absence of TNF- $\alpha(20 \mathrm{ng} / \mathrm{ml})$ for $24 \mathrm{~h}$. After treatment, the expression of Atg-7, Beclin-1 and LC3B was determined by western blotting. GAPDH was used as a loading control. (C) The quantification of the expression levels of autophagy-related proteins. Data are expressed as the means \pm SD of three independent experiments. ${ }^{*} P$ $<0.05$ compared with the TNF- $\alpha$ group ${ }^{\#} P<0.05$ compared with the control cells.

\subsection{Emodin attenuates TNF- $\alpha$-induced apoptosis and autophagy in C2C12} myoblasts through the activation of the phosphorylation of Akt

Akt is a critical factor in cellular survival, differentiation, and energy metabolism, and the phosphorylation of Akt can regulate apoptosis and autophagy [39-41]. The results presented in Fig. 4A and B show that, in the presence of TNF- $\alpha$, the expression of p-Akt (Ser-473) and p-Akt (Thr-308) was reduced, whereas emodin treatment resulted in the upregulation of the phosphorylated forms of Akt, and the group treated with $20 \mu \mathrm{M}$ emodin showed the highest level of phosphorylated Akt. Overall, these results suggest that the TNF- $\alpha$-induced apoptosis and autophagy of $\mathrm{C} 2 \mathrm{C} 12$ cells may be attenuated by emodin through the activation of the phosphorylation of Akt. 

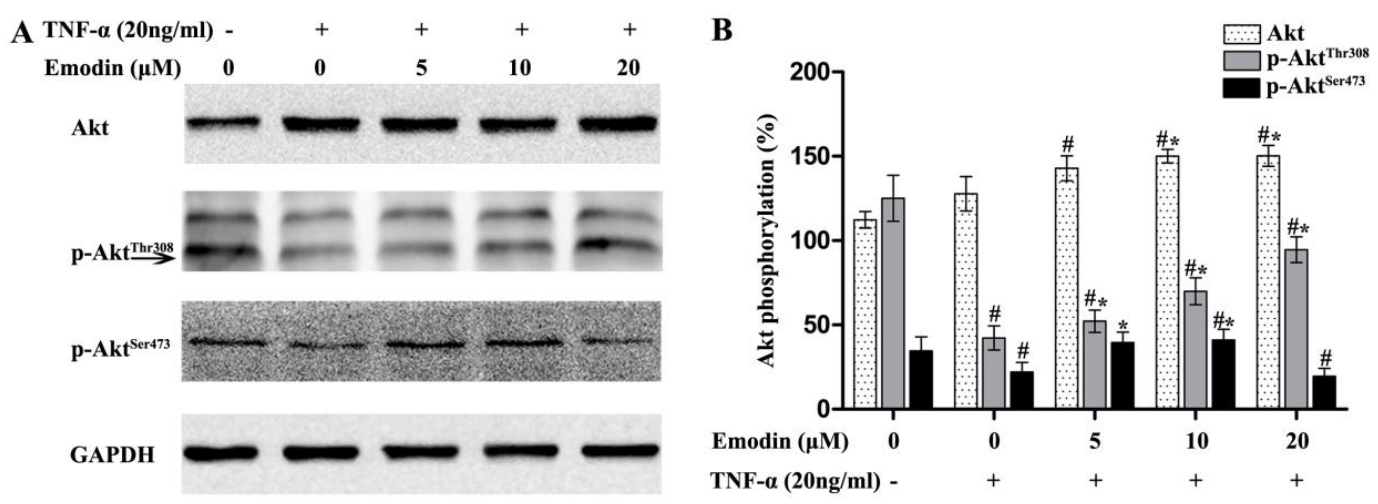

Fig. 4. Emodin increases the levels of phosphorylated Akt. C2C12 myoblasts were incubated with emodin in the presence or absence of TNF- $\alpha(20 \mathrm{ng} / \mathrm{ml})$ for $24 \mathrm{~h}$. (A) After treatment, the proteins from the total cell lysates were separated by SDS-PAGE gel electrophoresis and immunoblotted with antibodies against total Akt and phosphorylated Akt (Ser-473 and Thr-308). (B) The quantification of the expression levels of total Akt and phosphorylated Akt (Ser-473 and Thr-308). Data are expressed as the means \pm SD from at least three independent experiments. ${ }^{*} P<0.05$ compared with the TNF- $\alpha$ group ${ }_{2}{ }^{\#} P<0.05$ compared with the control cells.

\section{Discussion}

Apoptosis plays a significant role in age-related muscle atrophy [14, 42, 43]. Previous studies have shown that pathological levels of the pro-inflammatory cytokine TNF- $\alpha$ can inhibit myogenic differentiation and induce apoptosis [4, 7, 44]. However, apoptosis induced by TNF- $\alpha$ and its corresponding receptor-mediated signaling often overlaps with mitochondrion-mediated signaling. Both of these pathways can lead to cellular destruction by caspases [45]. In the mitochondrial apoptosis signaling pathway, pro-apoptotic (Bax and Bad) and anti-apoptotic (Bcl-2 and $\mathrm{Bcl}-\mathrm{xl})$ members of the $\mathrm{Bcl}-2$ family play important roles $[46,47]$. Bax assists in the release of cytochrome $\mathrm{c}$ from the mitochondrial intermembrane into the cytosol and the in activation of caspase [48]. In contrast, Bcl-2 acts to sustain mitochondrial 
integrity, suppressing the release of cytochrome $\mathrm{c}$ and subsequently inhibiting apoptosis [49]. Overexpression of Bcl-2 in cells has been reported to prevent the loss of mitochondrial potential, the release of cytochrome $\mathrm{c}$, and the activation of caspases, whereas Bax reduces these changes [48]. Therefore, striking a balance between the levels of expression of pro-apoptotic and anti-apoptotic proteins is of paramount importance for regulating the survival or death of cells [50]. Thus, the $\mathrm{Bcl}-2 / \mathrm{Bax}$ ratio is often used as an indicator of a cell's apoptotic potential; a high ratio protects against apoptosis and a low ratio favors apoptosis. The activation of caspases is a biochemical feature of apoptosis. Caspases are responsible for the proteolytic cleavage of a broad spectrum of cellular targets [10]. The initiator caspases (caspase-8, -9) are cleaved by stimulators of apoptosis and thereby activate executioner caspases (caspase-3), which results in small and large subunits generated by the cleaving. A caspase cascade occurs that leads to PARP (a DNA repair enzyme and a known caspase substrate) cleavage and DNA degradation [49]. In our study, we demonstrated that emodin could decrease pro-apoptotic Bax, cleaved-caspase 3 and cleaved-PARP expression and elevate anti-apoptotic $\mathrm{Bcl}-2$ in $\mathrm{C} 2 \mathrm{C} 12$ myoblasts. It is well known that ROS mediates the intracellular signaling of apoptotic proteolytic cascades [51]. Chronic and acute overproduction of ROS can induce a loss of $\Delta \Psi \mathrm{m}$, which is accompanied by the loss of cellular function and apoptosis [52]. Furthermore, it has been shown that enhanced production of ROS may induce a pro-apoptotic shift $\underline{\text { in }}$ the expression pattern of $\mathrm{Bcl}-2$ proteins as evidenced by a decreased Bcl-2/Bax ratio [53, 54]. Increased ROS production stimulates the pro-apoptotic factor Bax, resulting in the activation of the mitochondrial apoptotic pathway [55]. Our results show that emodin treatment resulted an increase in $\Delta \Psi \mathrm{m}$ and a decrease in ROS. Taken together, 
these findings suggest that emodin protects against TNF- $\alpha$-induced apoptosis through effects on the mitochondrial apoptotic pathway.

Autophagy is a complex catabolic process for lysosomal degradation of proteins and is essential for cellular survival, differentiation, development, and homeostasis [39]. It leads to the recycling of organelles and other cytoplasmic substances to provide metabolic precursors. Autophagy principally serves an adaptive role to protect organisms against diverse pathologies [39]. However, excessive stimulation of autophagy is deleterious and may lead to caspase-independent cell death [21]. It has been found that the excessive activation of autophagy aggravates muscle wasting by removing portions of the cytoplasm, proteins, and organelles [56]. TNF- $\alpha$ plays an important role in autophagy [57]. Therefore, tight control of TNF- $\alpha$-induced gene expression is needed to avoid the unbalanced induction of autophagy and muscle loss. To further clarify the protective effects of emodin against TNF- $\alpha$-induced autophagy in $\mathrm{C} 2 \mathrm{C} 12$ myoblasts, we measured the changes in LC3, Beclin-1 and Atg7 expression and found that the expression of LC3-II, Beclin-1 and Atg7 was decreased with emodin treatment, indicating that emodin treatment suppresses TNF- $\alpha$-induced autophagy in C2C12 myoblasts.

Increasing evidence indicates that the cross talk between autophagy and apoptosis is made especially complicated by the fact that they share many common regulatory factors, such as the PI3K/Akt/mTOR signaling pathway $[15,46,58-60]$. The activation of this pathway allows cells to inhibit apoptosis and autophagy, which might be responsible for malignant transformation and proliferation $[39,41]$. On the other hand, inhibition of the PI3K/Akt/mTOR signaling pathway causes cell death associated with apoptosis and/or autophagy [15]. Emodin has been reported to 
modulate the PI3K/Akt signaling pathway [29, 33]. In the present study, emodin increased the level of phosphorylated Akt. These data support the suggestion that the PI3K/Akt pathway might be involved in the anti-apoptotic and anti-autophagic actions of emodin.

In summary, the present study is the first to suggest that emodin protects against apoptosis and autophagy in TNF- $\alpha$-stimulated $\mathrm{C} 2 \mathrm{C} 12$ myoblasts and that this protection is associated with phosphorylated Akt. These findings demonstrate that emodin may be a potential therapeutic agent to improve muscle atrophy. MuRF1 and MAFbx have been demonstrated to be upregulated significantly in multiple models of skeletal muscle atrophy in rodents and humans [29, 33]. In addition, studies have shown that myotubes could be induced to undergo hypertrophy by the IGF/Akt pathway, which induces the protein synthesis required for muscle hypertrophy and blocks the up-regulation of MAFbx and MuRF1 that occurs during muscle atrophy $[29,33]$. Therefore, in future work, we will focus on studying atrophy-related signaling pathways and genes to further confirm the function of emodin in this process.

\section{Acknowledgement}

We acknowledge the financial support from the National Science Foundation of China (No. 81173457 81402801) and Guangdong (2014A030310250) and the scientific research projects of the Administration of Traditional Chinese Medicine of Guangdong (20141189) and Southern Medical University (PY2013N010 and C1031 898). We would like to thank Xiujie Liang and Xiduan Wei for their suggestions.

\section{References:}

[1] Thomas DR. Loss of skeletal muscle mass in aging: Examining the relationship of starvation, sarcopenia and cachexia. CLIN NUTR. 2007; 26:389-99.

[2] Fanzani A, Conraads VM, Penna F, Martinet W. Molecular and cellular mechanisms of skeletal muscle atrophy: an update. Journal of Cachexia, Sarcopenia and Muscle. 2012; 3:163-79. 
[3] Yuan J, Yu M, Li H, Long Q, Liang W, Wen S, et al. Autophagy contributes to IL-17-induced plasma cell differentiation in experimental autoimmune myocarditis. INT IMMUNOPHARMACOL. 2014; 18:98-105.

[4] Magee P, Pearson S, Allen J. The omega-3 fatty acid, eicosapentaenoic acid (EPA), prevents the damaging effects of tumour necrosis factor (TNF)-alpha during murine skeletal muscle cell differentiation. LIPIDS HEALTH DIS. 2008; 7:24.

[5] Sishi BJ, Engelbrecht AM. Tumor necrosis factor alpha (TNF-alpha) inactivates the PI3kinase/PKB pathway and induces atrophy and apoptosis in L6 myotubes. CYTOKINE. 2011; 54:173-84.

[6] LANGEN RCJ. Tumor necrosis factor-alpha inhibits myogenic differentiation through MyoD protein destabilization. The FASEB Journal. 2004; 18:227-37.

[7] Tolosa L, Morlá M, Iglesias A, Busquets X, Lladó J, Olmos G. IFN- $\gamma$ prevents TNF- $\alpha$-induced apoptosis in $\mathrm{C} 2 \mathrm{C} 12$ myotubes through down-regulation of TNF-R2 and increased NF- $\mathrm{B}$ activity. CELL SIGNAL. 2005; 17:1333-42.

[8] Biressi S, Molinaro M, Cossu G. Cellular heterogeneity during vertebrate skeletal muscle development. DEV BIOL. 2007; 308:281-93.

[9] Zhang M, Koishi K, Mclennan IS. Skeletal muscle fibre types: detection methods and embryonic determinants. Histology \& Histopathology. 1998; 13:201-7.

[10] Dupont-Versteegden EE. Apoptosis in skeletal muscle and its relevance to atrophy. World J Gastroenterol. 2006; 12:7463-6.

[11] Marzetti E, Wohlgemuth SE, Lees HA, Chung H, Giovannini S, Leeuwenburgh C. Age-related activation of mitochondrial caspase-independent apoptotic signaling in rat gastrocnemius muscle. MECH AGEING DEV. 2008; 129:542-9.

[12] Marzetti E, Groban L, Wohlgemuth SE, Lees HA, Lin M, Jobe H, et al. Effects of short-term GH supplementation and treadmill exercise training on physical performance and skeletal muscle apoptosis in old rats. Am J Physiol Regul Integr Comp Physiol. 2008; 294:R558-67.

[13] Dirks AJ, Leeuwenburgh C. The role of apoptosis in age-related skeletal muscle atrophy. SPORTS MED. 2005; 35:473-83.

[14] Marzetti E, Anne Lees H, Eva Wohlgemuth S, Leeuwenburgh C. Sarcopenia of aging: Underlying cellular mechanisms and protection by calorie restriction. BIOFACTORS. 2009; 35:28-35.

[15] Zhang DM, Liu JS, Deng LJ, Chen MF, Yiu A, Cao HH, et al. Arenobufagin, a natural bufadienolide from toad venom, induces apoptosis and autophagy in human hepatocellular carcinoma cells through inhibition of PI3K/Akt/mTOR pathway. CARCINOGENESIS. 2013; 34:1331-42.

[16] Tait SWG, Green DR. Mitochondrial Regulation of Cell Death. CSH PERSPECT BIOL. 2013; 5:a8706.

[17] Xu C, Zhang H, Liu C, Zhu Y, Wang X, Gao W, et al. Rapamycin inhibits Erk1/2-mediated neuronal apoptosis caused by cadmium. ONCOTARGET. 2015; 6:21452-67.

[18] Wang Y, Yu H, Zhang J, Ge X, Gao J, Zhang Y, et al. Anti-tumor effect of emodin on gynecological cancer cells. CELL ONCOL. 2015; 15:234-8.

[19] Sishi BJN, Engelbrecht A. Tumor necrosis factor alpha (TNF- $\alpha$ ) inactivates the PI3-kinase/PKB pathway and induces atrophy and apoptosis in L6 myotubes. CYTOKINE. 2011; 54:173-84.

[20] Dirks AJ, Leeuwenburgh C. Tumor necrosis factor $\alpha$ signaling in skeletal muscle: effects of age and caloric restriction. The Journal of Nutritional Biochemistry. 2006; 17:501-8.

[21] Levine B. Autophagy in cell death: an innocent convict? J CLIN INVEST. 2005; 115:2679-88.

[22] Degenhardt K, Mathew R, Beaudoin B, Bray K, Anderson D, Chen G, et al. Autophagy promotes tumor cell survival and restricts necrosis, inflammation, and tumorigenesis. CANCER CELL. 2006; 10:51-64.

[23] Sacheck JM, Hyatt JPK, Raffaello A, Jagoe RT, Roy RR, Edgerton VR, et al. Rapid disuse and denervation atrophy involve transcriptional changes similar to those of muscle wasting during systemic diseases. The FASEB Journal. 2006; 21:140-55.

[24] Jinghui Zhao JJBA. FoxO3 Coordinately Activates Protein Degradation by the Autophagic/Lysosomal and Proteasomal Pathways in Atrophying Muscle Cells. CELL METAB. 2007; 6:472-83.

[25] Shi Y, Wang D, Lu L, Yin Y, Wang M, Li C, et al. Ligustilide prevents the apoptosis effects of tumour necrosis factor-alpha during $\mathrm{C} 2 \mathrm{C} 12$ cell differentiation. INT IMMUNOPHARMACOL. 2014; 19:358-64.

[26] Wang D, Yin Y, Yang Y, Lv P, Shi Y, Lu L, et al. Resveratrol prevents TNF- $\alpha$-induced muscle atrophy via regulation of $\mathrm{Akt} / \mathrm{mTOR} / \mathrm{FoxO} 1$ signaling in $\mathrm{C} 2 \mathrm{C} 12$ myotubes. INT IMMUNOPHARMACOL. 2014; 19:206-13. 
[27] Shi Y, Xiao L, Yin Y, Wei L. Ligustilide inhibits tumour necrosis factor-alpha-induced autophagy during C2C12 cells differentiation. BIOMED PHARMACOTHER. 2015; 69:42-6.

[28] Wu L, Cai B, Zheng S, Liu X, Cai H, Li H. Effect of Emodin on Endoplasmic Reticulum Stress in Rats with Severe Acute Pancreatitis. INFLAMMATION. 2013; 36:1020-9.

[29] Lee S, Shin HK, Min YK, Kim SH. Emodin accelerates osteoblast differentiation through phosphatidylinositol 3-kinase activation and bone morphogenetic protein-2 gene expression. INT IMMUNOPHARMACOL. 2008; 8:741-7.

[30] Li D, Zhang N, Cao Y, Zhang W, Su G, Sun Y, et al. Emodin ameliorates lipopolysaccharideinduced mastitis in mice by inhibiting activation of NF- $\mathrm{B}$ and MAPKs signal pathways. EUR J PHARMACOL. 2013; 705:79-85.

[31] Yang Z, Zhou E, Wei D, Li D, Wei Z, Zhang W, et al. Emodin inhibits LPS-induced inflammatory response by activating PPAR- $\gamma$ in mouse mammary epithelial cells. INT IMMUNOPHARMACOL. 2014; $21: 354-60$.

[32] Feng H. Emodin inhibits tumor necrosis factor- $\alpha$-induced migration and inflammatory responses in rat aortic smooth muscle cells. INT J MOL MED. 2012.

[33] Zhang X, Zhang R, Lv P, Yang J, Deng Y, Xu J, et al. Emodin up-regulates glucose metabolism, decreases lipolysis, and attenuates inflammation in vitro. J DIABETES. 2015; 7:360-8.

[34] Lemasters JJ, Nieminen AL, Qian T, Trost LC, Elmore SP, Nishimura Y, et al. The mitochondrial permeability transition in cell death: a common mechanism in necrosis, apoptosis and autophagy. Biochim Biophys Acta. 1998; 1366:177-96.

[35] Chen D, Tang J, Khatibi NH, Zhu M, Li Y, Wang C, et al. Treatment with Z-Ligustilide, a Component of Angelica sinensis, Reduces Brain Injury after a Subarachnoid Hemorrhage in Rats. J PHARMACOL EXP THER. 2011; 337:663-72.

[36] Heo S, Yun H, Noh E, Park S. Emodin and rhein inhibit LIGHT-induced monocytes migration by blocking of ROS production. VASC PHARMACOL. 2010; 53:28-37.

[37] Keller CW, Fokken C, Turville SG, Lunemann A, Schmidt J, Munz C, et al. TNF- $\alpha$ Induces Macroautophagy and Regulates MHC Class II Expression in Human Skeletal Muscle Cells. J BIOL CHEM. 2011; 286:3970-80.

[38] Keller CW, Schmitz M, Münz C, Lünemann JD, Schmidt J. TNF- $\alpha$ upregulates macroautophagic processing of APP/ $\beta$-amyloid in a human rhabdomyosarcoma cell line. J NEUROL SCI. 2013; 325:103-7.

[39] Levine B, Kroemer G. Autophagy in the Pathogenesis of Disease. CELL. 2008; 132:27-42.

[40] Swaminathan JK, Khan M, Mohan IK, Selvendiran K, Niranjali Devaraj S, Rivera BK, et al. Cardioprotective properties of Crataegus oxycantha extract against ischemia-reperfusion injury. PHYTOMEDICINE. 2010; 17:744-52.

[41] Nakagawa A, Sullivan KD, Xue D. Caspase-activated phosphoinositide binding by CNT-1 promotes apoptosis by inhibiting the AKT pathway. NAT STRUCT MOL BIOL. 2014; 21:108290.

[42] Siu PM. Aging influences cellular and molecular responses of apoptosis to skeletal muscle unloading. AJP: Cell Physiology. 2005; 288:C338-49.

[43] Tina Wenz SGRR. Increased muscle PGC-1 $\alpha$ expression protects from sarcopenia and metabolic disease during aging. PNAS. 2009; 106:20405-10.

[44] KATE A. MEADOWS JMPH. Tumor Necrosis Factor- $\alpha$-Induced ApoptosisIs Associated With Suppression of Insulin-Like Growth Factor Binding Protein-5 Secretion in Differentiating Murine Skeletal Myoblasts. J CELL PHYSIOL. 2000; 330-37.

[45] Strasser A, Cory S, Adams JM. Deciphering the rules of programmed cell death to improve therapy of cancer and other diseases. EMBO J. 2011; 30:3667-83.

[46] Danial NN, Korsmeyer SJ. Cell Death: Critical Control Points. CELL. 2004; 116:205-19.

[47] Ellis RE, Yuan JY, Horvitz HR. Mechanisms and functions of cell death. Annu Rev Cell Biol. $1991 ; 7: 663-98$.

[48] Jurgensmeier JM, Xie Z, Deveraux Q, Ellerby L, Bredesen D, Reed JC. Bax directly induces release of cytochrome c from isolated mitochondria. Proc Natl Acad Sci U S A. 1998; 95:49975002.

[49] David L. Vaux SJK. Cell Death in Development. CELL. 1999; 96:245-54.

[50] Chai J, Xiong Q, Zhang P, Zheng R, Peng J, Jiang S. Induction of Ca2+ signal mediated apoptosis and alteration of IP3R1 and SERCA1 expression levels by stress hormone in differentiating C2C12 myoblasts. GEN COMP ENDOCR. 2010; 166:241-9.

[51] Kaysen GA. The Role of Oxidative Stress-Altered Lipoprotein Structure and Function and Microinflammation on Cardiovascular Risk in Patients with Minor Renal Dysfunction. J AM SOC NEPHROL. 2004; 15:538-48. 
[52] Alberto Pignone GFAD. The pathogenesis of inflammatory muscle diseases: On the cutting edge among the environment, the genetic background, the immune response and the dysregulation of apoptosis. AUTOIMMUN REV. 2002; 1:226-32.

[53] Mishra OP, Randis T, Ashraf QM, Delivoria-Papadopoulos M. Hypoxia-induced Bax and Bcl-2 protein expression, caspase-9 activation, DNA fragmentation, and lipid peroxidation in mitochondria of the cerebral cortex of newborn piglets: The role of nitric oxide. NEUROSCIENCE. 2006; 141:1339-49.

[54] Jamal Bouitbir FSAC, Schlagowski ABAE. Statins Trigger Mitochondrial ROS-Induced Apoptosis in Glycolytic Skeletal Muscle. Antioxidants \& Redox Signaling. 2014; 10:1-56.

[55] Antonsson B. Mitochondria and the Bcl-2 family proteins in apoptosis signaling pathways. Molecular and Cellular Biochemistry. 2004; 256/257:141-55.

[56] Sandri M. Autophagy in skeletal muscle. FEBS LETT. 2010; 584:1411-6.

[57] JIA G, CHENG G, GANGAHAR DM, AGRAWAL DK. Insulin-like growth factor-1 and TNF- $\alpha$ regulate autophagy through c-jun $\mathrm{N}$-terminal kinase and Akt pathways in human atherosclerotic vascular smooth cells. IMMUNOL CELL BIOL. 2006; 84:448-54.

[58] Beth Levine SSGK. Bcl-2 family members: Dual regulators of apoptosis and autophagy. AUTOPHAGY. 2008; 4(5):600-6.

[59] Pattingre S, Tassa A, Qu X, Garuti R, Liang XH, Mizushima N, et al. Bcl-2 Antiapoptotic Proteins Inhibit Beclin 1-Dependent Autophagy. CELL. 2005; 122:927-39.

[60] Kumar D, Das B, Sen R, Kundu P, Manna A, Sarkar A, et al. Andrographolide Analogue Induces Apoptosis and Autophagy Mediated Cell Death in U937 Cells by Inhibition of PI3K/Akt/mTOR Pathway. PLOS ONE. 2015; 10:e139657.

[61] Glass DJ. Molecular mechanisms modulating muscle mass. TRENDS MOL MED. 2003; 9:344-50.

[62] Luigi de Palma, Mario Marinelli, Matteo Pavan, Alessandro Orazi. Ubiquitin ligases MuRF1 and MAFbx in human skeletal muscle atrophy. Joint Bone Spine. 2008;75:53-7.

[63] Rodriguez J, Vernus B, Chelh I, Cassar-Malek I, Gabillard JC, Hadj Sassi A, et al. Myostatin and the skeletal muscle atrophy and hypertrophy signaling pathways. CELL MOL LIFE SCI. 2014; 71:4361-71. 

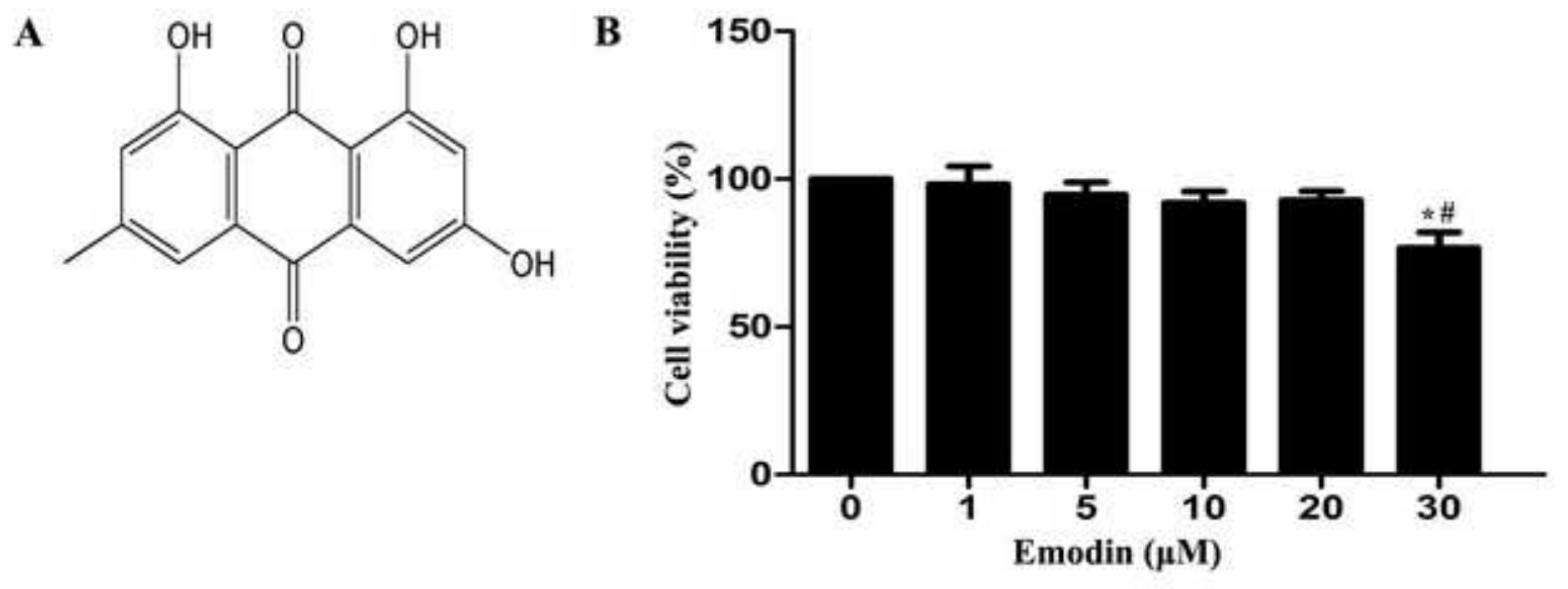

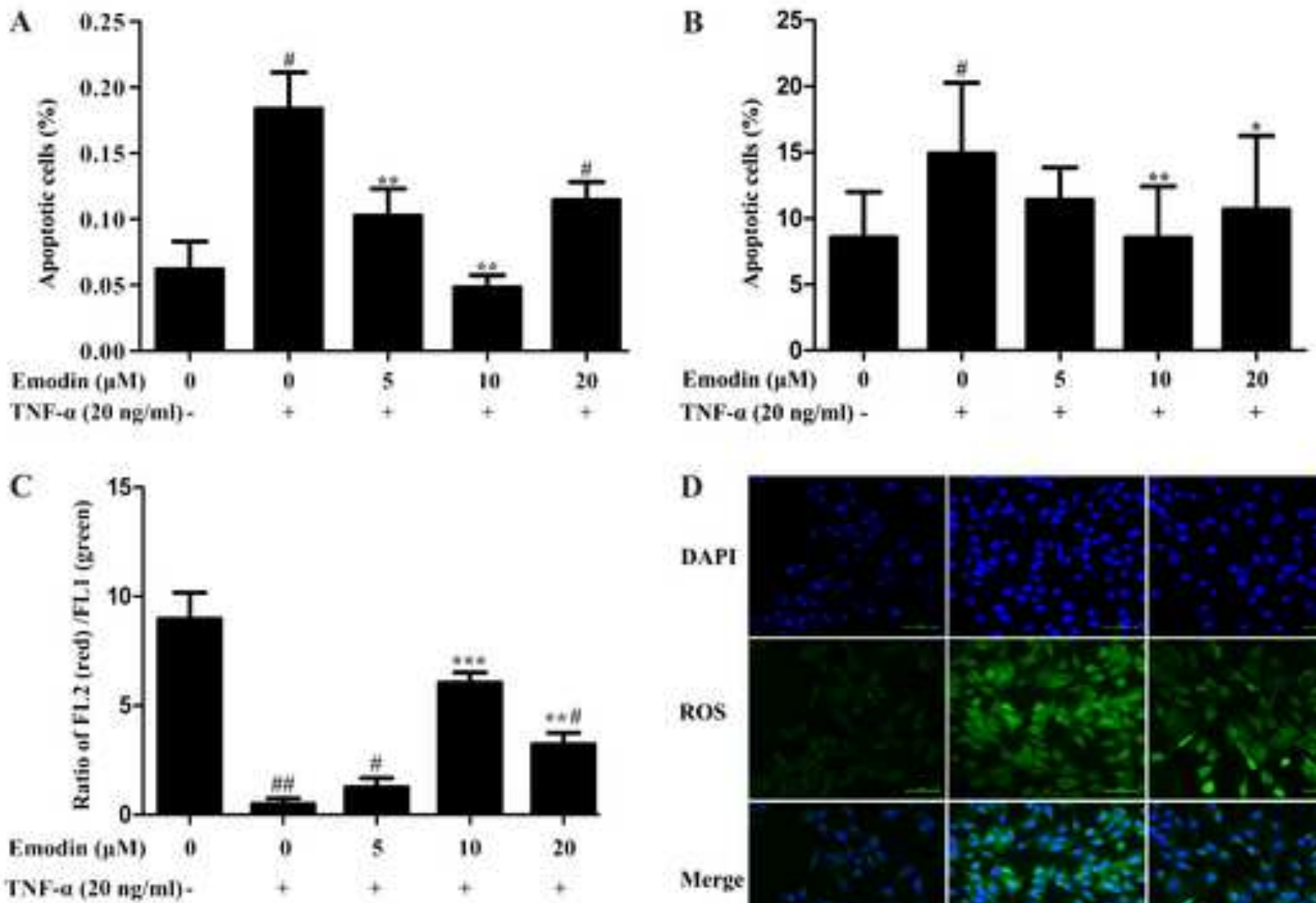

E

Bel-2

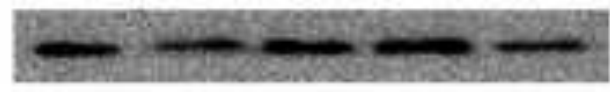

Bax

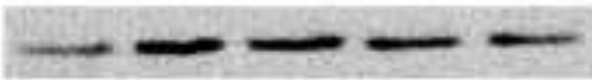

cleaved caspase?

PARP

cleaved PARP

GAPDH

Emodin (jM)
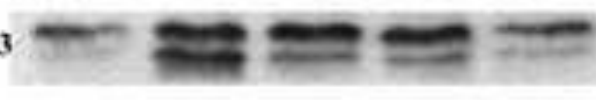

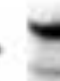
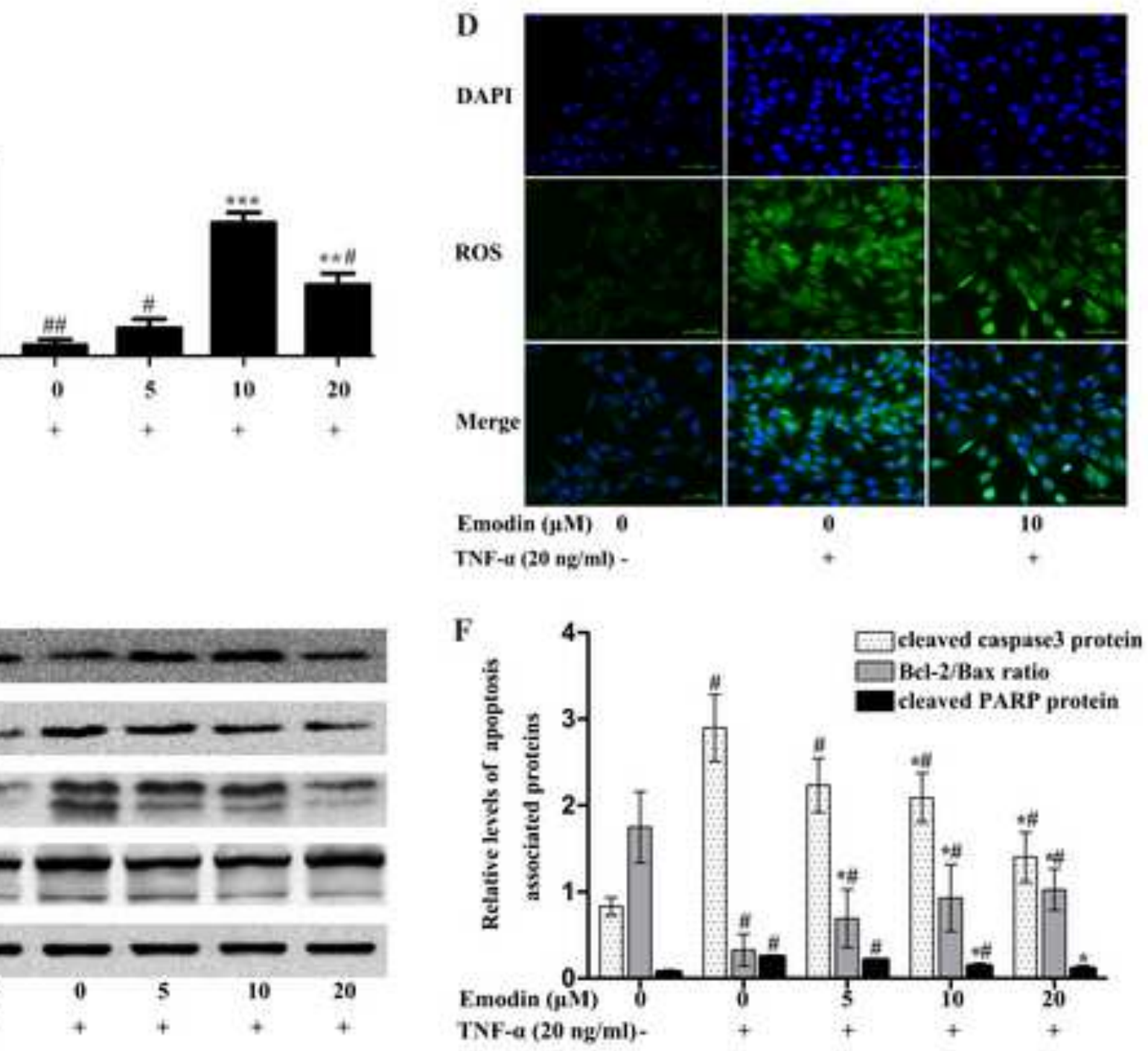
A TNF-a (20ngiml)

Emodin ( $\mu \mathrm{M}$ )

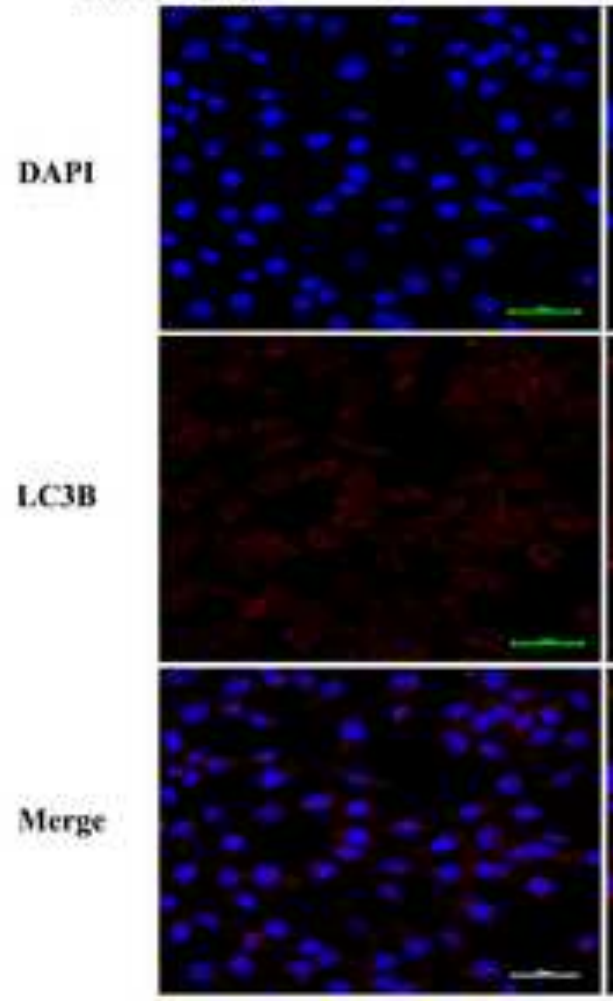

0
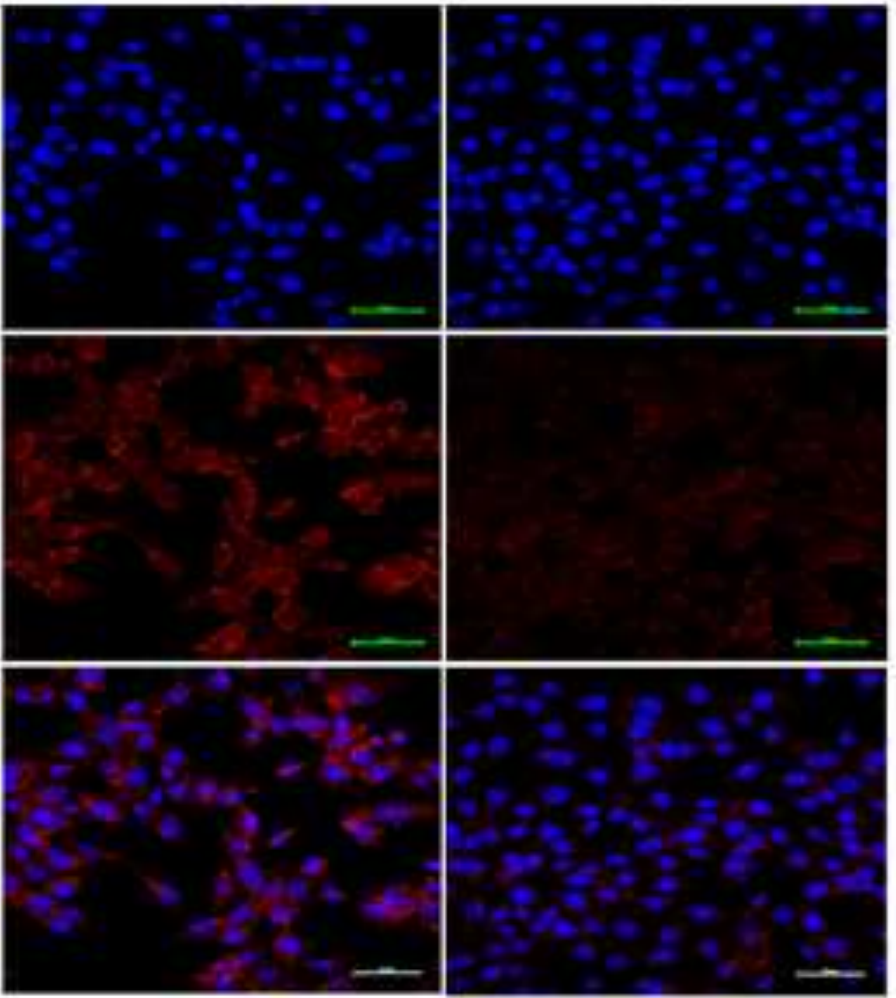

B TNF-a $(20 \mathrm{ng} / \mathrm{ml})$

Emodin ( $\mu \mathrm{M}$ )

Atg 7

Beclis-1

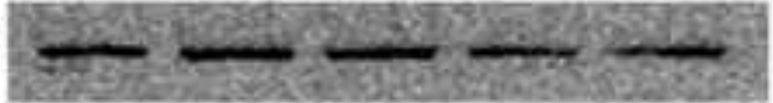

LC3-1

LC3-II

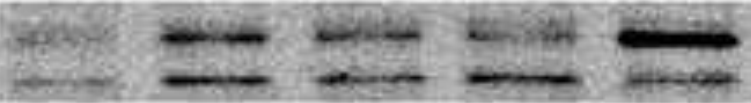

GAPDH

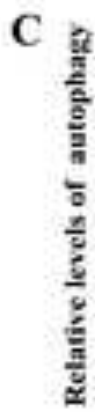

Emodin ( $\mu$ M)

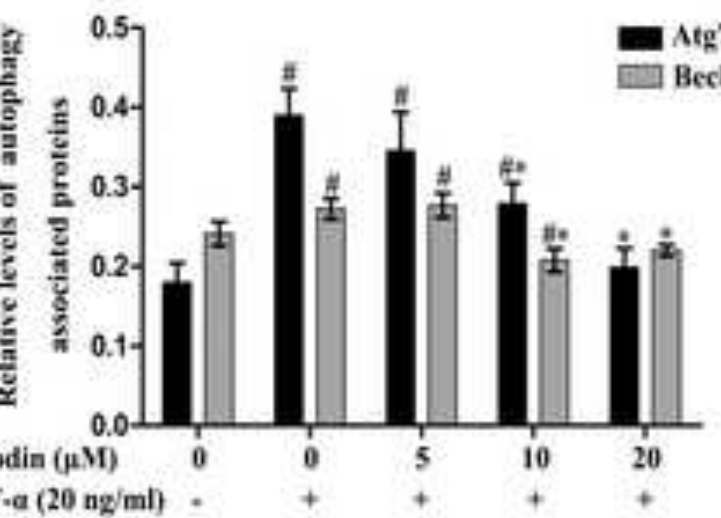

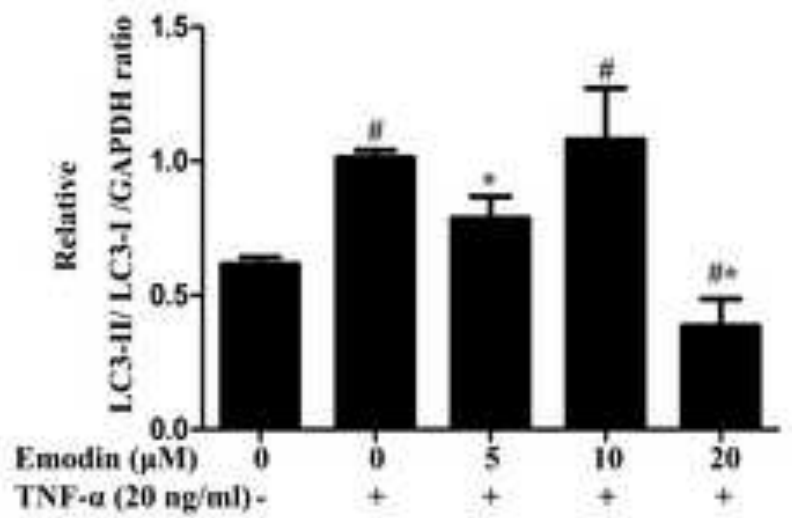




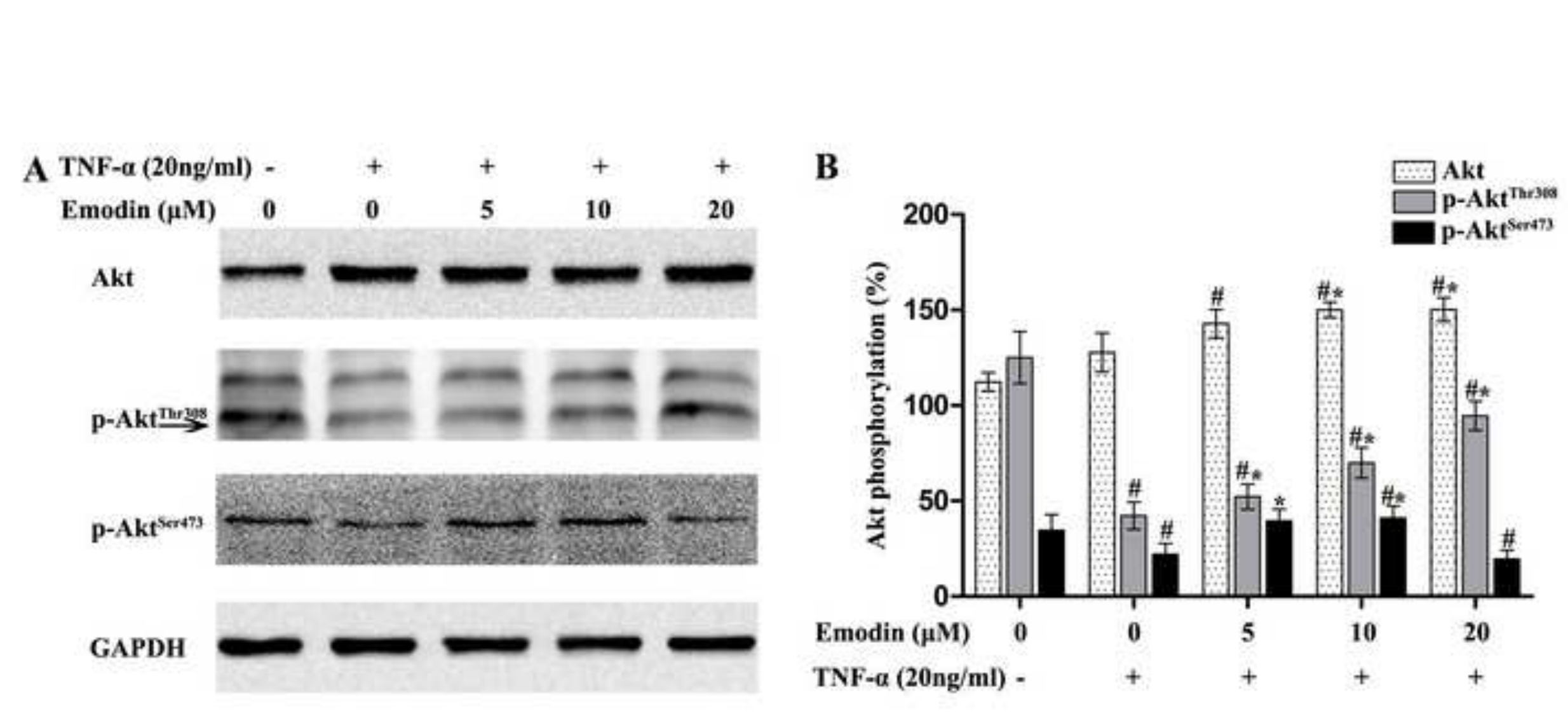

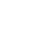

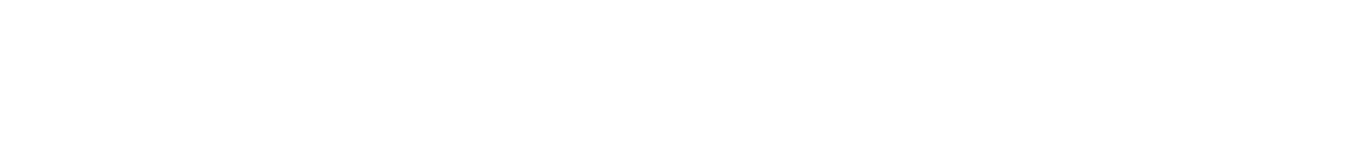


